Original Article

\title{
CYTOTOXIC METABOLITES OF ALTERNARIA ALTERNATA, AN ENDOPHYTE OF THE MEDICINAL PLANT BIDENS BIPINNATA
}

\author{
RANDA ABDOU1,2*, MOHAMED DAWOUD ${ }^{3}$ \\ 1Department of Pharmacognosy, Faculty of Pharmacy, Umm Al Qura University, Makkah, KSA, ${ }^{2}$ Department of Pharmacognosy, Faculty of \\ Pharmacy, Helwan University, Cairo, Egypt, ${ }^{3}$ Department of Pharmaceutics, Faculty of Pharmacy, Umm Al Qura University, Makkah, KSA \\ Email: randafathi@ymail.com
}

Received: 09 Nov 2019, Revised and Accepted: 22 Jan 2020

\begin{abstract}
Objective: Endophytes are widely spread in the plant kingdom and represent a very promising source of biologically active natural products. The medicinal plant Bidens bipinnata Lin. (Asteraceae) which is known for its anti-inflammatory, antifungal and antitumor effects has been chosen for the investigation of its endophyte to search for bioactive metabolites.
\end{abstract}

Methods: An endophytic Alternaria alternata species was isolated from the leaves of the plant B. bipinnata Lin. To investigate the metabolic profile of this endophytic fungus it was cultivated in several culture media as static and shaken culture. The antimicrobial and cytotoxic activities of the ethyl acetate extracts of the fungus were examined. Extracts exhibiting highest antimicrobial activities in agar diffusion assay and cytotoxicity against HeLa cancer cell line were subjected to activity-guided chromatographic fractionation for the identification of bioactive metabolites. A cytotoxic assay was performed on the isolated compounds against HeLa cancer cell lines as well as cytostatic activity tests against HUVEC and K-562 cell lines.

Results: Chromatographic fractionation resulted in the isolation and identification of alternariol and tentoxin from the extract of the fungus cultivated in medium M5 while sterigmatocystin was isolated in addition to alternariol and tentoxin from the extract of the fungus grown in medium M25. Both alternariol and sterigmatocystin proved to be of moderate cytotoxicity and weak cytostatic activity with alternariol showing higher cytotoxic activity than sterigmatocystin. Highest cytotoxicity against HeLa cell lines was observed for tentoxin with a $\mathrm{CC}_{50} \mathrm{of} 22.5 \mu \mathrm{g} / \mathrm{ml}$.

Conclusion: This study presents the isolation and identification of the bioactive metabolites alternariol, sterigmatocystin and tentoxin from the endophyte $A$. alternata in addition to the antifungal activity of the strain extract as well as the cytotoxic and cytostatic activities of the isolated metabolites against HeLa, HUVEC and K-562 cell lines, respectively.

Keywords: Alternariol, Sterigmatocystin, Tentoxin, Endophytes, Alternaria alternata, Bidens bipinnata

(C) 2020 The Authors. Published by Innovare Academic Sciences Pvt Ltd. This is an open access article under the CC BY license (http://creativecommons.org/licenses/by/4.0/) DOI: http://dx.doi.org/10.22159/ijpps.2020v12i3.36317. Journal homepage: https://innovareacademics.in/journals/index.php/ijpps

\section{INTRODUCTION}

Endophytes are considered as a promising source for bioactive metabolites and only few plant species of the entire plant kingdom on earth have been examined so far [1-3].

Plants having special uses and biological activities are considered as a promising source for study [4]. Accordingly, the medicinal plant Bidens bipinnata has been chosen for the investigation of its endophytic content. B. bipinnata $\mathrm{L}$. is a widely distributed herbaceous plant that was used in traditional medicine for the treatment of inflammation accompanying several diseases such as hepatitis and diabetes [5].

A study has been conducted to investigate the role of total flavonoids of $B$. bipinnata in suppressing tumor necrosis factor-alpha (TNF- $\alpha$ ) and nitric oxide (NO) release in HUVECs cultured with sera from active Henoch-Schonlein purpura (HSP) patients. Results showed that total flavonoids of the plant may inhibit the inflammatory mediators in HUVECs induced by sera from active HSP patients [5]. Furthermore, polyacetylenes from B. bipinnata were reported to exert antiinflammatory activities on lipopolysaccharide (LPS)-induced interleukin 1 and tumor necrosis factor (TNF- $\alpha$ ) production in macrophage (RAW264.7) cells [6]. In a recent study, the plant extract exerted inhibitory effects on human HepG2 cell lines and Hela cell lines with $\mathrm{IC}_{50}$ values of $14.80 \mu \mathrm{g} / \mathrm{ml}$ and $13.50 \mu \mathrm{g} / \mathrm{ml}$ respectively [7].

Since mainly the plant but not its endophytes has been studied so far and as it is a biologically active plant that could represent a promising source of bioactive endophytes according to the plant selection strategies identified by Strobel [4], it has been chosen for the investigation of its endpophytes. In a previous study an endophytic Khuskia oryzae species have been isolated from the stem parts of B. bipinnata and two bioactive oxylipins, as well as the mycotoxin sterigmatocystin, have been isolated from it [8].
This study presents the isolation and identification of biologically active metabolites of another endophytic fungus, Alternaria alternata from the leaves of B. bipinnata.

Alternaria fungi are widely spread in nature and have been reported to act as phytopathogens, plant pathogens, parasites, saprophytes and endophytes [9]. Accordingly, a wide variety of biological activities have been reported for Alternaria metabolites such as phytotoxic, cytotoxic, and antimicrobial properties [10-14]. Porritoxin isolated from an endophytic Alternaria species has been studied as a potential cancer chemopreventive agent [15]. Depudecin, an inhibitor of histone deacetylase (HDAC) from $A$. brassicicola, also showed antitumor potency $[16,17]$. Some Alternaria metabolites such as tenuazonic acid and tentoxin have been studied as herbicidal agents [18-20].

Due to the importance of culture medium composition for microbial production of secondary metabolites [21-23], it was necessary to use different culture media for the cultivation of this endophytic fungus. Thus, it was cultivated in three different culture media (M4, M5 and M25) under shaking and stationary conditions to investigate the effect of varying culture media and growth conditions on the production of secondary metabolites. HPLC chromatograms of the ethyl acetate (EtOAc) extracts of the obtained cultures showed different chemical patterns and different antimicrobial and cytotoxic activities in preliminary biological screening tests.

\section{MATERIALS AND METHODS}

The wildly growing plant material was collected near Cairo/Egypt and identified by Dr. Abdel Megid (Head of Department of Botany at the Museum of Agriculture, Cairo/Egypt). Leaves of the plant were cut into small pieces, washed with sterilized water, followed by treatment with $70 \%$ ethanol for $1-2$ min and air-drying under a 
laminar flow hood. This was performed in order to eliminate contaminants. Outer tissues were removed from the plant samples and the inner tissues were carefully dissected under sterile conditions and placed onto malt agar plates containing antibiotics. After four weeks of incubation, hyphal tips of the fungus were transferred to fresh malt agar medium. The fungus was cultivated on malt agar medium at room temperature for several days. When fungal hyphae almost covered the surface of the MA plate, cultures were stored at $4{ }^{\circ} \mathrm{C}$ for a maximum period of $6 \mathrm{mo}$, and then reinoculated onto fresh MA media.

Identification of the fungal strain was carried out at the Centraalbureau voor Schimmelcultures in the Netherlands using a molecular biological protocol by DNA amplification and sequencing of the internal transcribed spacer (ITS) region.

Large-scale fermentation (40 L) of the endophytic fungus was carried out under static conditions in two different culture media (M5 and M25). The first medium used for cultivation of the investigated fungus was M5, which was composed of glycerin (20 $\mathrm{g} / \mathrm{l})$, glucose $(2 \mathrm{~g} / \mathrm{l})$, peptone $(10 \mathrm{~g} / \mathrm{l})$ and sodium chloride $(0.5 \mathrm{~g} / \mathrm{l})$. In addition static cultures were also prepared in medium M25 which consisted of glucose $(10 \mathrm{~g} / \mathrm{l})$, malt extract $(20 \mathrm{~g} / \mathrm{l})$, soybean flour (2 $\mathrm{g} / \mathrm{l})$, yeast extract $(1 \mathrm{~g} / \mathrm{l})$, potassium dihydrogen phosphate $(1 \mathrm{~g} / \mathrm{l})$ and magnesium sulfate heptahydrate $(0.5 \mathrm{~g} / \mathrm{l})$. Extraction with ethyl acetate resulted in a dry weight of $15 \mathrm{~g}$ crude extract for the cultures in M5 and a yield of $17 \mathrm{~g}$ dry extract for the culture in M25. After defatting with $\mathrm{n}$-hexane final extracts of $10 \mathrm{~g}$ and $12 \mathrm{~g}$ were obtained for both cultures respectively. Both extracts were subjected to bioactivity guided chromatographic fractionation using hexane; ethyl acetate (9:1) followed by a gradual increase of polarity till elution with $100 \%$ ethyl acetate. Bioactive fractions were furthermore purified using Sephadex LH-20 followed by preparative HPLC using reversed-phase silica as a stationary phase and a mixture of acetonitrile and water as a mobile phase. These purification steps resulted in the isolation of $1.7 \mathrm{mg}$ of alternariol, $1.5 \mathrm{mg}$ of tentoxin and $1.4 \mathrm{mg}$ of sterigmatocystin.

Alternariol: reddish white needles, UV (MeOH) $\lambda_{\max } 206.1,255.8$, 299.8 and $339.7 \mathrm{~nm}$; HRESIMS $\mathrm{m} / z \quad 259.2106[\mathrm{M}+\mathrm{H}]^{+}$, calcd 259.2109 for $\mathrm{C}_{14} \mathrm{H}_{11} \mathrm{O}_{5}$.

20

Tentoxin: colourless needles, [a] $\mathrm{D}^{-117}$ (c 0.3, MeOH). UV (MeOH) $\lambda_{\max } 220,280,300 \mathrm{~nm}$. IR (film) vmax: 3350, 2950, 1450, 1670, 1630, 1520, 760, $700 \mathrm{~cm}^{-1}$. HRESIMS $\mathrm{m} / \mathrm{z}: 415.2254[\mathrm{M}+\mathrm{H}]^{+}$, calcd 415.2259, for $\mathrm{C}_{22} \mathrm{H}_{30} \mathrm{~N}_{4} \mathrm{O}_{4}$.

Sterigmatocystin: pale yellow powder, $[\alpha]_{\mathrm{D}}^{20}-363$ (c 1.0, $\left.\mathrm{CHCl}_{3}\right), \mathrm{UV}$ $(\mathrm{MeOH}) \lambda_{\max }(\log \epsilon) 233$ (27200), 248 (34000), 275sh (7700), 330 (19200) nm; IR (film): 3125, 1655, 1635, 1610, $1595 \mathrm{~cm}^{-1}$; HRESIMS $\mathrm{m} / \mathrm{z} 325.2506[\mathrm{M}+\mathrm{H}]^{+}$calcd $325.2510[\mathrm{M}+\mathrm{H}]^{+}$for $\mathrm{C}_{18} \mathrm{H}_{13} \mathrm{O}_{6}$.

\section{Antimicrobial screening}

Antimicrobial activities were examined by agar diffusion tests according to the literature $[24,25]$ and minimal inhibitory concentration (MIC) was determined using the broth microdilution method according to the NCCLS guidelines [26]

\section{Antiproliferative and cytotoxic assays}

The cells used in this assay were HUVEC (ATCC CRL-1730), K-562 (DSM ACC 10) and HeLa (DSM ACC 57) which were cultured in
DMEM (CAMBREX 12-614F), RPMI 1640 (CAMBREX 12-167F) and RPMI 1640 (CAMBREX 12-167F) respectively. The culture medium of these cells was supplemented with $10 \mathrm{ml} \mathrm{l}^{-1}$ ultraglutamine 1 (Cambrex 17-605E/U1), $500 \mathrm{\mu l} \mathrm{l}^{-1}$ gentamicin sulfate (CAMBREX 17$518 Z$ ), and $10 \%$ heat-inactivated fetal bovine serum (PAA A15-144) at $37^{\circ} \mathrm{C}$ in high-density polyethylene flasks (NUNC 156340).

\section{Antiproliferative assay}

Before dilution in DMEM, the test substances were dissolved in DMSO. After soft trypsinization the adherent cells were harvested at the logarithmic growth phase using $0.25 \%$ trypsin in PBS containing $0.02 \%$ EDTA (Biochrom KG L 2163). Approximately 10.000 cells were seeded with $0.1 \mathrm{ml}$ culture medium per well of the 96-well microplates for each experiment (NUNC 167008).

\section{Cytotoxic assay}

HeLa cells were pre-incubated for $48 \mathrm{~h}$ without the test substances for the cytotoxic assay. After the pre-incubation time dilutions of the compounds were carried out carefully on the subconfluent monolayers of HeLa cells. In a humidified atmosphere and $5 \% \mathrm{CO}_{2}$ cells were incubated with dilutions of the test substances for $72 \mathrm{~h}$ at $37^{\circ} \mathrm{C}$.

\section{Method of evaluation}

To estimate the influence of chemical compounds on cell proliferation of K-562, determination of the numbers of viable cells present in multiwell plates was carried out via CellTiter-Blue ${ }^{\circledR}$ assay. To measure the metabolic capacity of the cells, resazurin was used as an indicator of cell viability. It was observed that viable cells of untreated control retain the ability to reduce resazurin into resorufin, which is highly fluorescent, while nonviable cells do not generate a fluorescent signal since they rapidly lose metabolic capacity and do not reduce the indicator dye. Under these

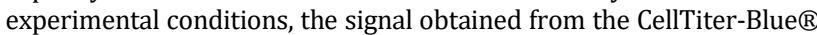
reagent is proportional to the number of viable cells. Glutaraldehyde was used to fix adherent HUVEC and HeLa cells and a $0.05 \%$ solution of methylene blue was used for for $15 \mathrm{~min}$ to stain them. The stain was eluted with $0.2 \mathrm{ml}$ of $0.33 \mathrm{~N} \mathrm{HCl}$ in the wells after gentle washing. SUNRISE microplate reader (TECAN) was used to measure optical densities at $660 \mathrm{~nm}$. $\mathrm{GI}_{50}$ and $\mathrm{CC}_{50}$ values were determined as being where the dose-response curve intersected the $50 \%$ line, compared to untreated control. Magellan (TECAN) software was used to perform the comparisons of the different values.

\section{RESULTS AND DISCUSSION}

The pure fungal strain was cultivated in three different culture media (M4, M5 and M25) both as shaken and as stationary culture, in order to examine the effect of different growth conditions on the secondary metabolite production of this endophytic strain. The extracts obtained for the fungal strain after cultivation in each medium were tested for antimicrobial activity against several microbial strains ( $S$. salmonicolor, $K$. marxianus, C. albicans, $A$. niger, A. fumigatus, $P$. avellaneum and A. terreus) (table 1 ). Highest antimicrobial activity was observed for the strain cultivated in medium M25 as a static culture. Extracts of shaken cultures were less active than static culture extracts. The obtained fungal extracts after cultivation in different media were subjected to a cytotoxic assay against HeLa cancer line. Highest cytotoxicity was observed for the extract of the fungus cultivated in medium M25 (fig. 1).

Table 1: Antimicrobial activitya of extracts of different cultures of Alternaria alternata

\begin{tabular}{|c|c|c|c|c|c|c|c|}
\hline Strain & S. salmonicolor & K. marxianus & C. albicans & A. niger & A. fumigatus & P. avellaneum & A. terreus \\
\hline Extract of stationary culture in M25 & 17 & 28 & 0 & 22 & 16 & 18 & 23 \\
\hline Extract of stationary culture in M5 & 13 & 17 & 0 & 0 & 12 & 17 & 18 \\
\hline Extract of stationary culture in M4 & 10 & 13 & 0 & 0 & 0 & 15 & 13 \\
\hline Extract of shaken culture in M25 & 13 & 18 & 24 & 20 & 14 & 13 & 20 \\
\hline Extract of shaken culture in M4 & 12 & 12 & 0 & 0 & 0 & 12 & 10 \\
\hline Extract of shaken culture in M5 & 12 & 16 & 18 & 0 & 12 & 10 & 14 \\
\hline Nystatin & 25 & 28 & 24 & 20 & 20 & 20 & 20 \\
\hline
\end{tabular}

$\mathrm{a}=$ measured in terms of the diameter of the inhibition zone in millimeters 


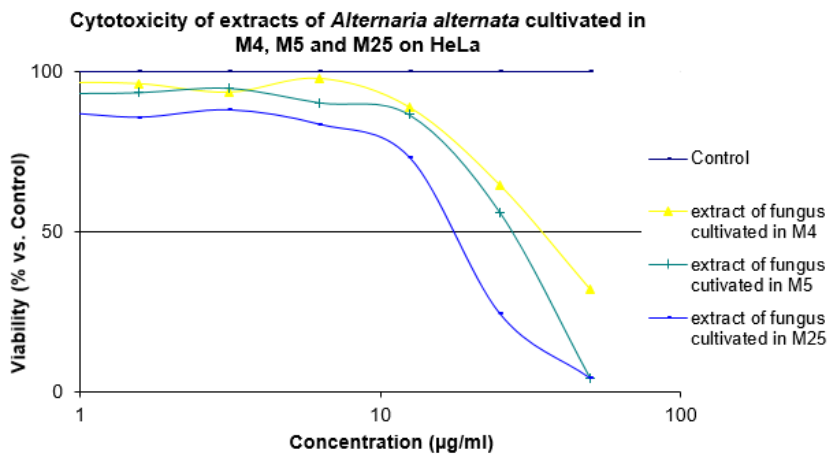

Fig. 1: Cytotoxicity of Alternaria extracts on Hela cell line

Activity guided chromatographic fractionation resulted in the isolation of the bioactive secondary metabolites of this fungal strain. The fungus grown in media M5 and M25 produced two common major secondary metabolites.

For the first compound a molecular formula of $\mathrm{C}_{14} \mathrm{H}_{11} \mathrm{O}_{5}(\mathrm{~m} / \mathrm{z} 259.2106$ $\left.[\mathrm{M}+\mathrm{H}]^{+}\right)$was determined by HRESIMS thus indicating 10 degrees of unsaturation. The number of carbons and hydrogens suggested by HRESIMS was in agreement with the number of signals detected in the ${ }^{13} \mathrm{C}$ NMR and ${ }^{1} \mathrm{H}$ NMR data (table 2). The ${ }^{1} \mathrm{H}$ NMR spectrum exhibited signals for four aromatic hydrogens at $\delta 6.4,6.6,6.7$ and $7.2 \mathrm{ppm}$; one methyl group at $\delta 2.7 \mathrm{ppm}$ and three phenolic hydroxyl groups at $\delta 10.3$, 10.8 and $11.7 \mathrm{ppm}$. Each two of the four aromatic protons were meta coupled with each other thus indicating the presence of two different aromatic rings. The ${ }^{13} \mathrm{C}$ NMR spectrum exhibited signals for a methyl group ( $\delta 25.23 \mathrm{ppm})$, eight olefinic carbons $(\delta 97.40,100.86,101.59$, $104.3,108.95,117.52,138.12,138.32 \mathrm{ppm})$, four olefinic carbon atoms bearing oxygen atoms $(\delta 152.61,158.41,164.06,164.69 \mathrm{ppm})$ and a carbonyl group ( $\delta 165.39 \mathrm{ppm}$ ). From the HMBC correlations, it was observed that one phenyl ring contained the two meta positioned protons at $\delta 7.2$ and $6.4 \mathrm{ppm}$ together with the two hydroxyls at $\delta 10.8$ and $11.7 \mathrm{ppm}$. This was concluded from the correlations observed between H-4 $(\delta 6.4 \mathrm{ppm})$ and C-6, 2, 3 and those of H-6 ( $\delta 7.2 \mathrm{ppm})$ with $\mathrm{C}-2,4,7$ and 1 '. Furthermore HMBC correlations were observed for the second phenyl group suggesting its substitution by one hydroxyl and one methyl group due to the correlations observed between $\mathrm{H}-3^{\prime}(\delta 6.6 \mathrm{ppm})$ and $\mathrm{C}^{\prime} \mathbf{1}^{\prime}, 4^{\prime}, 5^{\prime}, 6^{\prime}$ and for H-5 ( $\left.\delta 6.7 \mathrm{ppm}\right)$ with $\mathrm{C}^{\prime} \mathbf{1}^{\prime}, 3^{\prime}, 4^{\prime}, 7^{\prime}$. The upfield shift of C-2 ( $\delta 97.40 \mathrm{ppm})$ suggests its connection to a carbonyl group while the downfield shift observed for $\mathrm{C}-2$ ' $(\delta 138.32 \mathrm{ppm})$ indicates its connection to an ether group. According to literature data the deduced structure identified the isolated compound as alternariol (fig. 2) [27].

Alternariol is considered as a mycotoxin that has been previously isolated from several Alternaria species reported of infecting various fruits, such as tomatoes, olives, mandarins, melons, peppers and apples [28].
In addition, alternariol was previously isolated from a mangrove endophytic fungus from the South China Sea Coast and was reported to have strong cytotoxic activity against $\mathrm{KB}$ cell lines with an $\mathrm{IC}_{50}$ value of $4.82 \mu \mathrm{g} \mathrm{ml}^{-1}$. Antifungal activity and choline esterase inhibitory activity have also been reported for it [29]. Further investigation showed that alternariol [26] has been identified as a topoisomerase I and II poison which might contribute to the impairment of DNA integrity in human colon carcinoma cells [30]. It induced cell death by activation of the mitochondrial pathway of apoptosis in human colon carcinoma cells [31]. A more recent study investigated the mechanism of action of immune suppression of alternariol. It was found to suppress lipopolysaccharide (LPS)induced NF- $\mathrm{KB}$ pathway activation in THO-1 derived macrophages, decrease secretion of proinflammatory cytokines IL-8, IL-6 and to induce secretion of anti-inflammatory IL-10. In absence of LPS stimulus alternariol was found to increase IL-10 transcription only. Consequently it was concluded that alternariol is capable of repressing inflammation in an inflamed environment by targeting the NF- $\kappa B$ signaling pathway [32]. Furthermore, alternariol belongs to the toxins of Alternaria, which has phytotoxic properties and is important in the development of some plant disease processes such as black spot and seedling chlorosis [29].<smiles>Cc1cc(O)cc2oc(=O)c3c(O)cc(O)cc3c12</smiles>

Fig. 2: Chemical structure of alternariol

Table 2: NMR spectroscopic data (125 MHz, DMSO-d6) of alternariol

\begin{tabular}{|c|c|c|c|}
\hline Position & $\delta^{13} \mathrm{C}$ & $\delta^{1} \mathrm{H}(\mathrm{in} \mathrm{Hz})$ & HMBC \\
\hline 1 & 138.1, qC & & \\
\hline 2 & $97.4, \mathrm{qC}$ & & \\
\hline 3 & $164.7, \mathrm{qC}$ & & \\
\hline 4 & $100.9, \mathrm{CH}$ & $6.4, d(1.95)$ & $2,3,6$ \\
\hline 5 & 164.1, qC & & \\
\hline 6 & 104.3, CH & $7.2, d(1.95)$ & $2,4,7,1$ \\
\hline 7 & $165.4, \mathrm{qC}$ & & \\
\hline 1 & $109.0, \mathrm{qC}$ & & \\
\hline 2 & $138.3, \mathrm{qC}$ & & \\
\hline 3 & 101.6, CH & $6.6, d(2.60)$ & $1^{\prime}, 4^{\prime}, 5^{\prime}, 6^{\prime}$ \\
\hline 4 & 158.4, qC & & \\
\hline 5 & $117.5, \mathrm{CH}$ & $6.7, d(2.45)$ & $1^{\prime}, 3^{\prime}, 4^{\prime}, 7^{\prime}$ \\
\hline $6^{\prime}$ & $152.6, \mathrm{qC}$ & & \\
\hline 7 & $25,2, \mathrm{CH}_{3}$ & $2.7, s$ & $6,8,9$ \\
\hline $\mathrm{OH}$ & & $10.3, s$ & $3,4,5$ \\
\hline $\mathrm{OH}$ & & $10.8, s$ & $4,6,7$ \\
\hline $\mathrm{OH}$ & & $11.7, s$ & $2,3,4$ \\
\hline
\end{tabular}


Another major metabolite was produced by the fungus cultivated in M25 but was not observed in HPLC chromatograms of extracts of the fungus grown in M4 or M5. This compound appeared as a yellow solution in methanol and a molecular formula of $\mathrm{C}_{18} \mathrm{H}_{13} \mathrm{O}_{6}(\mathrm{~m} / \mathrm{z}$ $325.2506[\mathrm{M}+\mathrm{H}]^{+}$) was determined for it by HRESIMS. The ${ }^{1} \mathrm{H}-\mathrm{NMR}$ spectrum showed eight proton signals, a hydroxyl proton appearing at $\delta 13.28 \mathrm{ppm}$ indicating the presence of a chelated phenolic hydroxyl group and a methoxy group at $\delta 56.88 \mathrm{ppm}$. The ${ }^{13} \mathrm{C}-\mathrm{NMR}$ data (table 3) revealed the presence of 18 carbon signals and thus together with the ${ }^{1} \mathrm{H}-\mathrm{NMR}$ confirmed the suggested molecular formula. The HMBC correlations (table 3) clearly revealed the first part of the structure as being a benzo- $x$-pyrone. The downfield shift of C-7 and C-2 indicates their connection to oxygen atoms and thus reveals this part of the structure as being a tetrahydrodifurano ring system. By comparing the obtained structure with literature data it was found to be the mycotoxin sterigmatocystin (fig. 3), which has been previously isolated from several Aspergillus species like Aspergillus versicolor and Aspergillus multicolor [33]. Through the xanthone nucleus attached to a bifuran structure, it closely resembles the aflatoxins and has similarly been shown to be toxic to mice [34], rats [35] monkeys [36], ducklings [34] and is carcinogenic and mutagenic when injected or fed to rats [35]. Sterigmatocystin and has been detected in wheat [36] and coffee beans [37]. It belongs to the main 20 mycotoxins that are known to occur in foodstuffs at significant levels and frequency to be of food safety concern [33]. These mycotoxins have been reported to be produced by five fungal genera: Aspergillus, Penicillium, Fusarium, Alternaria and Claviceps [33].

A cytotoxic assay against HeLa cancer cell line was performed on the isolated compounds and observed results showed that both alternariol and sterigmatocystin exerted moderate cytotoxicity against HeLa cell lines and weak cytostatic activity against both HUVEC and K-562 cell lines with alternariol exerting higher cytotoxic and cytostatic activities (fig. 4). A $\mathrm{CC}_{50}$ value of more than $50 \mu \mathrm{g} \mathrm{ml}^{-1}$ and $\mathrm{GI}_{50}$ values of more than 50 and $44.7 \mu \mathrm{g} \mathrm{ml}^{-1}$ were observed for alternariol in the cytotoxic and cytostatic assay against HUVEC and K-562 cell lines respectively (fig. 4).<smiles>COc1cc2c(c3oc4cccc(O)c4c(=O)c13)[C]1C=COC1O2</smiles>

Fig. 3: Chemical structure of sterigmatocystin

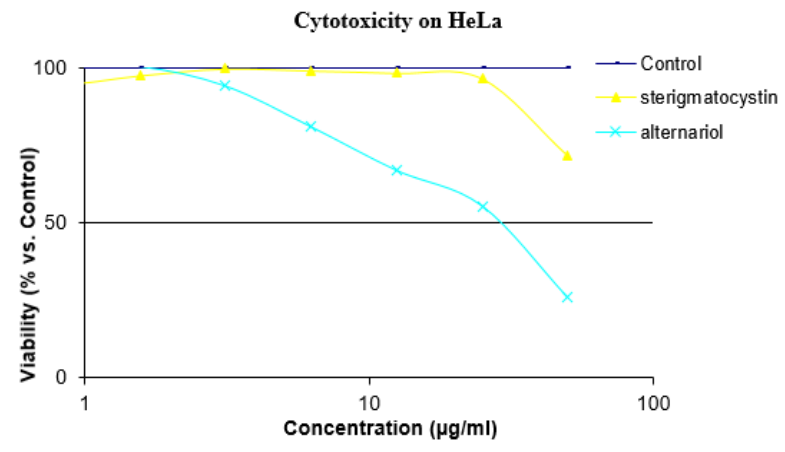

Antiproliferative Effect on HUVEC

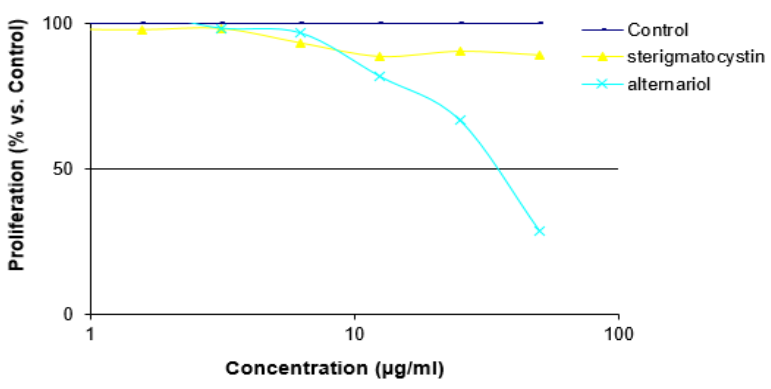

Antiproliferative Effect on K-562

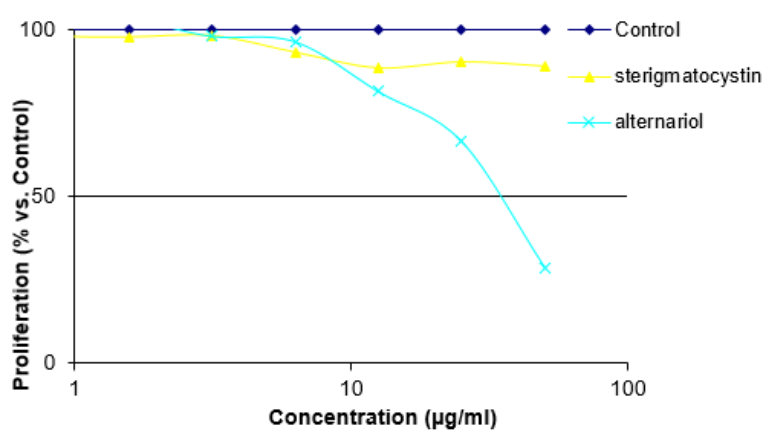

Fig. 4: Antiproliferative and cytotoxic activities of sterigmatocystin and alternariol 
Table 3: NMR spectroscopic data (150 MHz, DMSO-d6) of sterigmatocystin

\begin{tabular}{|c|c|c|c|}
\hline Position & $\delta^{13} \mathrm{C}$ & $\delta^{1} \mathrm{H}(\mathrm{J}$ in $\mathrm{Hz})$ & HMBC \\
\hline 1 & $110.8, \mathrm{CH}$ & $6.72, d$ & $8,17,9$ \\
\hline 2 & 106.6, qC & & \\
\hline 3 & 180.5, qC & & \\
\hline 4 & 136.3, $\mathrm{CH}$ & $7.62, t$ & $8,4,9$ \\
\hline 5 & 161.4, qC & & \\
\hline 6 & 162.9, qC & & \\
\hline 7 & 102.7, CH & $5.53, t$ & 3,15 \\
\hline 8 & 153.4, qC & & \\
\hline 9 & 105.0, qC & & \\
\hline 10 & 145.7, CH & $6.74, d$ & 9,17 \\
\hline 11 & $113.4, \mathrm{CH}$ & $6.90, d$ & $15,13,16,5,17$ \\
\hline 12 & 154.5, qC & & \\
\hline 13 & 106.6, $\mathrm{CH}$ & $7.00, d$ & $4,9,7,14,17$ \\
\hline 14 & 164.5, the & & \\
\hline 15 & 91.1, CH & $6.71, s$ & $8,1,13,12$ \\
\hline 16 & 108.3, qC & & \\
\hline 17 & $47.3, \mathrm{CH}$ & 4.86, $d$ & $16,5,11$ \\
\hline 18 & $56.9, \mathrm{OCH}_{3}$ & $3.89, s$ & 1 \\
\hline
\end{tabular}

The second main active constituent of the strain extracts obtained after cultivated in both M25 and M5 was found to be tentoxin (fig. 5). A molecular weight of $414 \mathrm{~g} / \mathrm{mol}$ (base peak at $415.23[\mathrm{M}+\mathrm{H}]^{+}$in the HPLC-MS) was suggested for the compound. By dereplication with authentic samples, it has been found to have an identical UV chromatogram to that of tentoxin (fig. 5). Also the IR spectrum and chromatographic properties were identical to those of tentoxin. This metabolite is a phytotoxin, which causes chlorosis in the seedlings of many plants [38]. Chemically, tentoxin is cyclo-[L-leucyl- $N$-methyl(Z)-dehydrophenylalanylglycyl- $N$-methyl-L-alanyl]. Since dihydrotentoxin has almost no chlorotic effect, the presence of the styrene structure in the dehydrophenylalanyl residue is essential for the chlorotic activity exerted by tentoxin [38].

A cytotoxic assay of tentoxin against HeLa cancer cell line was carried out and results revealed strong cytotoxicity for tentoxin with a $\mathrm{CC}_{50}$ of $22.5 \mu \mathrm{g} / \mathrm{ml}$ (fig. 6). This result is in agreement with previously conducted studies on tentoxin which stated that it exerted cytotoxic activity against both lung cancer cell line A549 and breast cancer cell line MDA-MB-231[39]. Previous studies also reported cytotoxic activities of Alternaria alternata against cultured tobacco BY-2 cells and detected the production of tentoxin by the fungus. The phytotoxin was reported to exert potent inhibition of the chloroplastic ATP synthase of certain plant species [40].

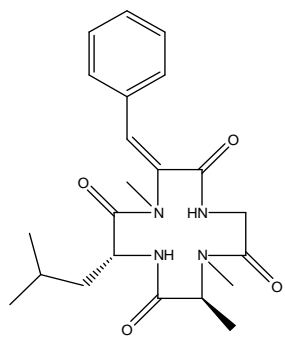

Fig. 5: Chemical structure of tentoxin

Cytotoxic activity of tentoxin on HeLa cell line

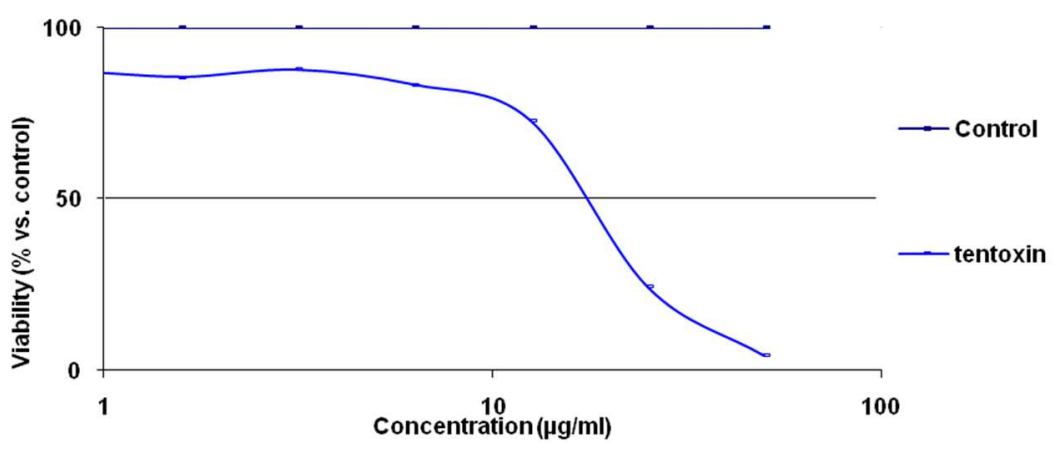

Fig. 6: Cytotoxic activity of tentoxin on HeLa cell line

Now the question arises about the role of these bioactive metabolites in the plant-endophyte interaction. Several hypotheses have been made to find an answer to this question. It has been suggested that endophytes may contribute to their host plant by producing many bioactive substances to provide protection that helps the host plant to survive stressful conditions. Some endophytes were found to be capable of increasing the hosts' effects on other plant species co-growing with them which compete with them for nutritional sources and habitat [4]. This could be the reason why dominant plant species were found to harbor special endophytes that support them in their competition with other species [4]. Indeed, this might be true for the plant B. bipinnata, as it is known to be a dominant, widely spreading species distributed in many regions of the world [41], which could be referred to the bioactive metabolites produced by its endophyte. Therefore, the detected production of bioactive natural products, especially cytotoxic and antifungal compounds by the fungal endophyte of $B$. bipinnata suggests their possible role in protecting themselves from competitors and the host plant from invaders.

At the time the endophyte was isolated from the plant, it was free from any symptoms of diseases, which could be due to the absence of pathogenic endophytes or due to the presence of latent pathogens. This assumption is based on previous hypotheses 
suggesting that it is possible to isolate a latent pathogen from an asymptomatic plant proposing that some pathogens may develop from endophytes [42].

This could explain the detection of phytotoxins such as tentoxin, sterigmatocystin, and alternariol known to cause chlorosis in plants, as secondary metabolites of the endophytic strain Alternaria alternata, from healthy samples of the plant Bidens bipinnata. It could be assumed that these toxins are produced by latent pathogens which are waiting for a suitable time of reduced immune response of the plant or senescence to exert their pathogenic effects, since being isolated as an endophyte, does not exclude the possibility that a fungus may become pathogenic when the host is stressed or senescent [42].

\section{CONCLUSION}

In conclusion, the endophyte Alternaria alternata has been isolated from the leaves of the medicinal plant Bidens bipinnata and its extract was found to exert antifungal activity against several fungal species, cytotoxicity against HeLa cell line as well as weak cytostatic activities against HUVEC and K-562 cell lines. Bioactivity-guided chromatographic fractionation resulted in the isolation and identification of alternariol, sterigmatocystin and tentoxin as bioactive metabolites of this fungal endophyte. Results of this study support previously made assumption of possible protective effects of endophytes on their host.

\section{FUNDING}

Nil

\section{AUTHORS CONTRIBUTIONS}

Randa Abdou performed the study steps, evaluated the research results and wrote the manuscript. Mohamed Dawoud analyzed data.

\section{CONFLICTS OF INTERESTS}

The authors report no conflicts of interest in this work.

\section{REFERENCES}

1. Guo ZF, TT Guo, M Guo. Preparation of molecularly imprinted adsorptive resin for trapping of ligustrazine from the traditional Chinese herb ligusticum chuanxiong Hort. Anal Chim Acta 2008;612:136-43.

2. Bose P, U Gowrie. Assessment of bioactive metabolites from the root endophyte isolated from casuarina junghuhniana miq. Asian J Pharm Clin Res 2017;10:137-43.

3. Devi BRK, E Elizabeth. Pharmacophoric screening of various endophytic fungal metabolites. Asian J Pharm Clin Res 2017;10:140-6.

4. Strobel G, B Daisy, U Castillo, J Harper. Natural products from endophytic microorganisms. J Nat Prod 2004;67:25768.

5. Yan Boa. Total flavonoids of Bidens bipinnata L. a traditional Chinese medicine inhibits the production of inflammatory cytokines of vessel endothelial cells stimulated by sera from henoch-schonlein purpura patients. J Pharm Pharmacol 2012;64:882-7.

6. Wang X, CG, Pan C, Deng Z, Ge J, Li N, et al. Polyacetylenes from bidens bipinnata L. and their biological activities. Phytochem Lett 2014;7:198-201.

7. Yang QH. Study on in vitro anti-tumor activity of bidens bipinnata l. extract. Afr J Tradit Complement Altern Med 2013;10:543-9.

8. Abdou R, Shaker K. Bioactive metabolites of the endophyte Khuskia oryzae isolated from the medicinal plant Bidens bipinnata. Asian J Pharm Life Sci 2013;3:137-45.

9. Thomma BPHJ. Alternaria spp: from general saprophyte to specific parasite. Mol Plant Pathol 2003;4:225-36.

10. RNS. Phytotoxins produced by microbial plant pathogens. Nat Prod Rep 2007;24:127-44.

11. Strange RN. Phytotoxins produced by plant pathogens. Nat Prod Rep 2007;24:127-44.

12. Mobius NHC. Fungal phytotoxins as mediators of virulence. Curr Opin Plant Biol 2009;12:390-8.
13. Brase SEA, Keck J, Nising CF. Chemistry and biology of mycotoxins and related fungal metabolites. Chem Rev 2009;109:3903-90.

14. Tsuge T. Host-selective toxins produced by the plant pathogenic fungus Alternaria alternata. FEMS Microbiol Rev 2013;37:44-66

15. Horiuchi M. Porritoxins, metabolites of Alternaria porri, as antitumor-promoting active compounds. Nat Prod Res 2006;20:161-6.

16. Monneret C. Histone deacetylase inhibitors. Eur J Med Chem 2005;40:1-13.

17. Lakshmi AI. Histone deacetylase inhibitors in cancer therapy: an update. Int J Pharm Sci Rev Res 2011;10:38-44.

18. Stierle A, G Strobel, D Stierle. Taxol and taxane production by Taxomyces andreanae, an endophytic fungus of pacific yew. Science 1993;260:214-6.

19. Liebermann BER, Pinet E. Isotentoxin, a conversion product of the phytotoxin tentoxin. Phytochem Lett 1996;42:1537-40.

20. Sanodiya BS. Isolation and characterization of tenuazonic acid produced by alternaria alternata, a potential bioherbicidal agent for control lantana camara. J Plant Prot Res 2010;50:133-9.

21. Bills GF. Analyses of microfungal diversity from a user's perspective. Can J Bot 1995;73:S33-S41.

22. Knight V. Diversifying microbial natural products for drug discovery. Appl Microbiol Biotechnol 2003;62:446-58.

23. Zhang HW, YC Song, RX Tan. Biology and chemistry of endophytes. Nat Prod Rep 2006;23:753-71.

24. Afonin S. 4-fluorophenylglycine as a label for $19 \mathrm{~F}$ NMR structure analysis of membrane-associated peptides. ChemBioChem 2003;4:1151-63.

25. Wayne PA. Reference method for broth dilution susceptibility testing of filamentous fungi. Approved Standard M38-A, USA, NCCls; 2002.p. 22.

26. Raistrick H, CE Stickings, $R$ Thomas. Studies in the biochemistry of microorganisms. 90. Alternariol and alternariol monomethyl ether, metabolic products of Alternaria tenuis. Biochem J 1953;55:421-33.

27. Griffin GF, FS Chu. Toxicity of the Alternaria metabolites alternariol, alternariol methyl ether, altenuene, and tenuazonic acid in the chicken embryo assay. Appl Environ Microbiol 1983;46:1420-2.

28. Doupnik BJr, EK Sobers: mycotoxicosis: toxicity to chicks of Alternaria longipes isolated from tobacco. Appl Microbiol Biotechnol 1968;16:1596-7.

29. Ostry V. Alternaria mycotoxins: an overview of chemical characterization, producers, toxicity, analysis and occurrence in foodstuffs. World Mycotoxin J 2008;1:175-88.

30. Bensassi F. Cell death induced by the alternaria mycotoxin alternariol. Toxicol In Vitro 2012;26:915-23.

31. J Lou, L Fu, Y Peng, L Zhou. Metabolites of alternaria fungi and their bioactivities. Molecules 2013;18:5891-935.

32. Kollarova J, Cenk E, Schmutz CMD. The mycotoxin alternariol suppresses lipopolysaccharide-induced inflammation in THP-1 derived macrophages targeting the NF- $\mathrm{\kappa B}$ signalling pathway. Molec Toxicol 2018;92:3347-58.

33. Lillehoj EB, A Ciegler. Biological activity of sterigmatocystin. Mycopathol Mycol Appl 1968;35:373-6.

34. Purchase IF, JJ Van Der Watt. Acute toxicity of sterigmatocystin to rats. Food Cosmet Toxicol 1969;7:135-9.

35. Van Der Watt JJ, IF Purchase. Subacute toxicity of sterigmatocystin to rats. S Afr Med J 1970;44:159-60.

36. Dickens F, HE Jones, HB Waynforth. Oral, subcutaneous and intratracheal administration of carcinogenic lactones and related substances: the intratracheal administration of cigarette tar in the rat. Br J Cancer 1966;20:134-44.

37. Scott PM, W Van Walbeek, B Kennedy, D Anyeti: mycotoxins (ochratoxin A, citrinin, and sterigmatocystin) and toxigenic fungi in grains and other agricultural products. J Agric Food Chem 1972;20:1103-9.

38. Shigenori Kumazawa, Mok Ryeon Ahn, Takunori Fujimoto, M Kato. Radical-scavenging activity and phenolic constituents of propolis from different regions of argentina. Nat Prod Res 2010;24:804-12. 
39. KI-Bong Oh, Yasuo Tajima, Mikako Saito, IL-Moo Chang, H Matsuoka. Cytotoxicity of extracts from alternaria alternata against cultured tobacco by-2cells. Biocontrol Sci 2002;7:127-30.

40. Steyn PS. Mycotoxins, general view, chemistry, and structure. Toxicol Lett 1995;82-83:843-51.
41. Schulz B, C Boyle. The endophytic continuum. Mycol Res 2005;109:661-86.

42. Kogel KH, P Franken, R Huckelhoven. Endophyte or parasitewhat decides? Curr Opin Plant Biol 2006;9:358-63. 